\title{
An assessment of Prostate Cancer Research International: Active Surveillance (PRIAS) criteria for active surveillance of clinically low-risk prostate cancer patients
}

\author{
Vitor da Silva, MD'; Ilias Cagiannos, $M D^{1}$; Luke T. Lavallée, MD',2; Ranjeeta Mallick, PhD'; \\ Kelsey Witiuk, MSc'; Sonya Cnossen, MSc'; James A. Eastham, MD; Dean A. Fergusson, PhD; \\ Chris Morash, MD'; Rodney H. Breau, MD ${ }^{1,2}$
}

'University of Ottawa, Division of Urology, Department of Surgery, Ottawa, ON, Canada; ${ }^{2}$ Ottawa Hospital Research Institute, Ottawa, ON, Canada; ${ }^{3}$ Memorial Sloan Kettering Cancer Centre, Urology Service, Department of Surgery, New York, NY, United States

Cite as: Can Urol Assoc J 2017;11 (8):238-43. http://dx.doi.org/10.5489/cuaj.4093

\section{Abstract}

Introduction: Active surveillance is a strategy to delay or prevent treatment of indolent prostate cancer. The Prostate Cancer Research International: Active Surveillance (PRIAS) criteria were developed to select patients for prostate cancer active surveillance. The objective of this study was to compare pathological findings from PRIAS-eligible and PRIAS-ineligible clinically low-risk prostate cancer patients.

Methods: A D'Amico low-risk cohort of 1512 radical prostatectomy patients treated at The Ottawa Hospital or Memorial Sloan Kettering Cancer Centre between January 1995 and December 2007 was reviewed. Pathological outcomes (pT3 tumours, Gleason sum $\geq 7$, lymph node metastases, or a composite) and clinical outcomes (prostate-specific antigen [PSA] recurrence, secondary cancer treatments, and death) were compared between PRIAS-eligible and PRIAS-ineligible cohorts.

Results: The PRIAS-eligible cohort ( $n=945)$ was less likely to have Gleason score $\geq 7$ (odds ratio [OR] 0.61; 95\% confidence interval [Cl] 0.49-0.75), pT3 (OR 0.41; 95\% Cl 0.31-0.55), nodal metastases (OR 0.37; 95\% Cl 0.10-1.31), or any adverse feature (OR 0.56; 95\% CI 0.45-0.69) compared to the PRIAS-ineligible cohort. The probability of any adverse pathology in the PRIAS-eligible cohort was $41 \%$ vs. $56 \%$ in the PRIAS-ineligible cohort. At median followup of 3.7 years, 72 (4.8\%) patients had a PSA recurrence, 24 $(1.6 \%)$ received pelvic radiation, and $13(0.9 \%)$ received androgen deprivation. No difference was detected for recurrence-free and overall survival between groups (recurrence hazard ratio [HR] 0.71; 95\% Cl 0.46-1.09 and survival HR 0.72; 95\% Cl 0.36-1.47).

Conclusions: Low-risk prostate cancer patients who met PRIAS eligibility criteria are less likely to have higher-risk cancer compared to those who did not meet at least one of these criteria.

\section{Introduction}

Prostate-specific antigen (PSA) screening has resulted in a dramatic increase in the diagnosis of prostate cancer. ${ }^{1}$ While there has been a decline in prostate cancer mortality, there has also been an increase in detection of clinically insignificant tumours. Indeed, morbidity associated with diagnosis and treatment of low-risk prostate cancer is one of the primary arguments against routine prostate cancer screening. ${ }^{2}$

Active surveillance is an increasingly accepted strategy to prevent invasive therapy in patients with clinically lowrisk disease. ${ }^{3-5}$ Active surveillance implies some form of active patient monitoring, with more invasive interventions reserved for disease reclassification. Clearly, the benefits of active surveillance need to be balanced against the risks of delayed treatment for those patients who are ultimately found to have more aggressive tumours at subsequent biopsy or prostatectomy.

Several groups have described criteria for identifying patients who are the best candidates for active surveillance. ${ }^{6-12}$ One of the largest groups is the Prostate Cancer Research International: Active Surveillance (PRIAS) program that includes over 50 hospitals and almost 2000 patients. ${ }^{13}$ The objective of this study was to compare the pathological findings after prostatectomy of PRIAS-eligible and PRIASineligible clinically low-risk prostate cancer patients.

\section{Methods}

Institutional ethics approvals were obtained prior to study commencement. Consecutive radical prostatectomy patients treated at the Ottawa Hospital or Memorial Sloan Kettering Cancer Centre between January 1995 and December 2007 were eligible for inclusion. This study period was chosen to include patients diagnosed in the PSA screening era, but 
prior to routine use of active surveillance at these institutions. Patients were eligible if they had low-risk disease as defined by the D'Amico risk criteria (PSA less than $10 \mathrm{ng} / \mathrm{ml}$, clinical tumour stage $\leq \mathrm{CT} 2 \mathrm{a}$, and biopsy Gleason score $\leq 6$ ). Patients were excluded if they had clinically intermediate- or high-risk disease or if they had incomplete information to determine D'Amico risk group. Patients were also excluded if they received preoperative prostate radiation or androgen deprivation, had less than a 10-core biopsy performed, or had greater than six months between diagnosis and surgery.

\section{Baseline characteristics}

Preoperative factors, including age, PSA, PSA density (PSAD), clinical stage, and number of positive biopsy cores, were obtained from prospectively populated institutional clinical databases. The most recent PSA test prior to biopsy was used for analyses. Clinical stage was determined by the operating surgeon and documented in the medical record. PSAD was defined as the serum PSA concentration divided by the transrectal ultrasound estimated prostate volume.

\section{Outcomes}

Pathological outcomes included tumours that extended outside of the prostate (pT3), Gleason score $\geq 7$, lymph node metastases, or a composite of pT3, Gleason score $\geq 7$, or nodal metastases. The composite outcome was evaluated because some clinicians would consider any one of these adverse pathological attributes to be clinically important, warranting treatment for healthy patients with a long life expectancy. Post-treatment clinical outcomes included recurrence (defined as PSA $\geq 0.2 \mathrm{ng} / \mathrm{ml}$, any post-prostatectomy radiation, any androgen deprivation, or prostate cancer-related death), and death from any cause. Cause of death was abstracted from death certificates or the medical record. Postoperative assessments were generally performed every three months for the first year, every six months for the second year, and annually thereafter.

\section{Analyses}

Univariable and multivariable logistic regression was performed to determine associations between baseline characteristics and outcomes. The PRIAS criteria for active surveillance are defined as clinical stage T1/T2, Gleason $\leq 6$, PSA $<10 \mathrm{ng} / \mathrm{ml}, \leq 2$ positive biopsy cores, and PSAD $<0.2 \mathrm{ng} /$ $\mathrm{ml} .{ }^{12}$ The patients who satisfied all PRIAS criteria (PRIASeligible cohort) were compared to those who did not satisfy one or more of the PRIAS criteria (PRIAS-ineligible cohort). Cumulative incidence of recurrence and death were estimated for each group using the Kaplan-Meier method and compared using the log-rank test and Cox proportional hazards models. For recurrence, patients were censored at last followup or non-prostate cancer death. For death, patients were censored at last followup. No adjustment was made for multiple testing and $p$ values $\leq 0.05$ were considered statistically significant. All statistical analyses were conducted using SAS software version 9.4 (SAS Institute, Cary, NC, U.S.).

\section{Results}

During the study period, 9915 patients underwent radical prostatectomy at The Ottawa Hospital (TOH) and Memorial Sloan-Kettering Cancer Centre (MSKCC). Of these, 1512 (TOH 181; MSKCC 1331) had D'Amico low-risk disease and complete data to assess PRIAS criteria status (Fig. 1). The mean patient age was 59 (standard deviation [SD] 7) years, and mean PSA was 4.8 (SD 2.2) $\mathrm{g} / \mathrm{mL}$. Baseline patient characteristics stratified by PRIAS-eligible $(n=945)$ or PRIASineligible $(n=567)$ are presented in Table 1.

\section{Adverse prostatectomy pathology}

Of the 1512 clinically low-risk patients included in the study, $651(43.7 \%)$ had a Gleason score $\geq 7,219(14.5 \%)$

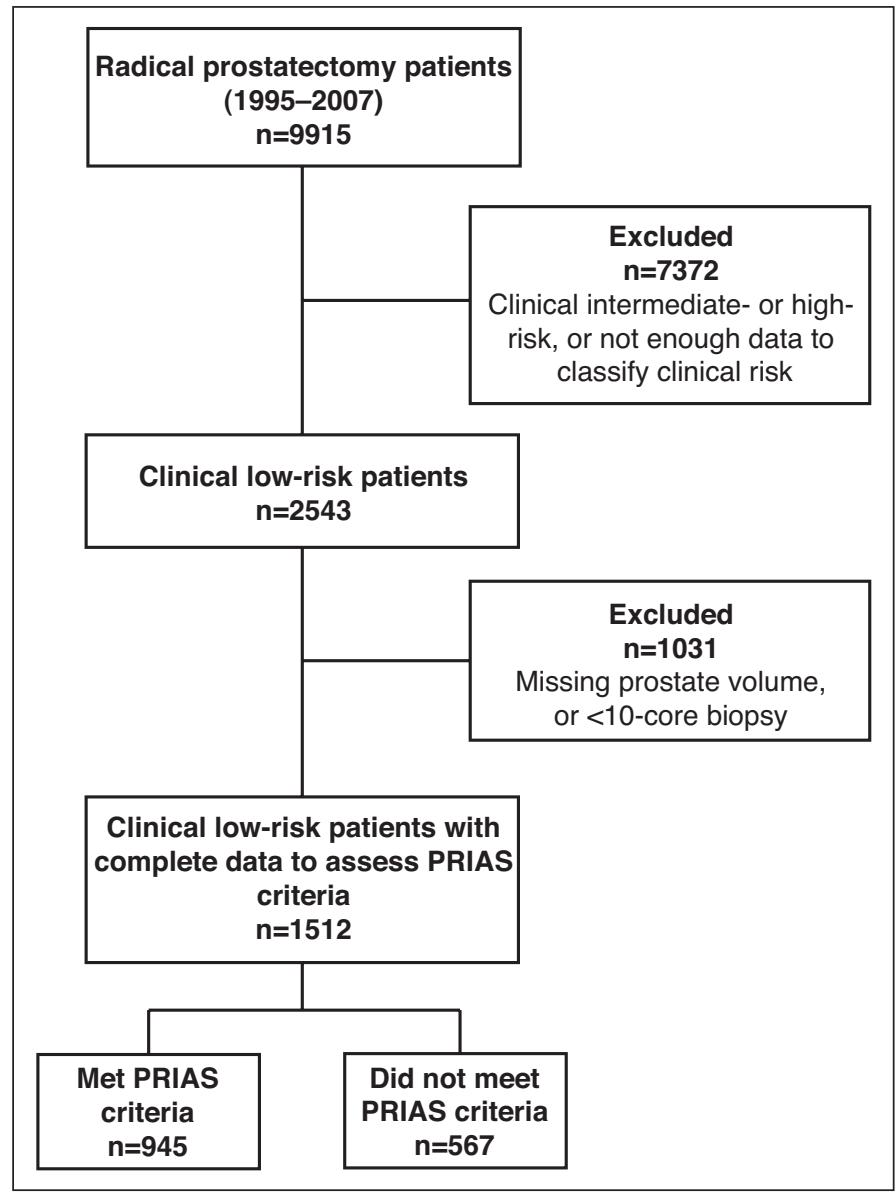

Fig. 1. Flow diagram of patients included/excluded from study cohort. PRIAS: Prostate Cancer Research International: Active Surveillance. 


\begin{tabular}{|c|c|c|c|c|}
\hline & $\begin{array}{c}\text { Total } \\
\mathrm{n}=1512\end{array}$ & $\begin{array}{l}\text { PRIAS-eligible } \\
n=945\end{array}$ & $\begin{array}{l}\begin{array}{c}\text { PRIAS-ineligible } \\
n=567\end{array} \\
\text { e }\end{array}$ & $\mathbf{p}$ \\
\hline Mean age (SD), years & $58.8(6.9)$ & $58.6(6.7)$ & $59.3(7.3)$ & 0.07 \\
\hline Median preoperative PSA (IQR), ng/mL & $4.7(3.4,6.3)$ & $4.6(3.2,6.0)$ & $4.9(3.7,6.8)$ & $<0.0001$ \\
\hline Median prostate volume (IQR), cc & $46.4(36.2,60)$ & $49.5(40.0,63.0)$ & $41.5(32.7,53.0)$ & $<0.0001$ \\
\hline$<25, \mathrm{n}(\%)$ & $78(5.2)$ & $33(3.5)$ & $45(7.9)$ & \multirow{3}{*}{$<0.0001$} \\
\hline $25-50, \mathrm{n}(\%)$ & $828(54.7)$ & 469 (49.6) & 359 (63.3) & \\
\hline$>50, \mathrm{n}(\%)$ & $606(40.1)$ & $443(46.9)$ & $163(28.8)$ & \\
\hline Median PSA density (IQR) & $0.1(0.06,0.14)$ & $0.09(0.06,0.12)$ & $0.11(0.07,0.18)$ & $<0.0001$ \\
\hline $\begin{array}{l}<0.2 \mathrm{ng} / \mathrm{mL}, \mathrm{n}(\%) \\
>0.2 \mathrm{ng} / \mathrm{mL}, \mathrm{n}(\%)\end{array}$ & $\begin{array}{c}1393(92.1) \\
119(7.9)\end{array}$ & $\begin{array}{c}945(100) \\
0(0)\end{array}$ & $\begin{array}{l}448(79.0) \\
119(21.0)\end{array}$ & $<0.0001$ \\
\hline \multicolumn{5}{|l|}{ Number of positive biopsy cores (\%) } \\
\hline 1 & $647(42.8)$ & $596(63.1)$ & $51(9.0)$ & $<0.0001$ \\
\hline 2 & $379(25.1)$ & 349 (36.9) & $30(5.3)$ & $<0.0001$ \\
\hline 3 & $185(12.2)$ & $0(0)$ & $185(32.6)$ & $<0.0001$ \\
\hline 4 & $105(6.9)$ & $0(0)$ & 105 (18.5) & $<0.0001$ \\
\hline$\geq 5$ & $196(13.0)$ & $0(0)$ & 196 (34.6) & $<0.0001$ \\
\hline \multicolumn{5}{|l|}{ Clinical stage, $\mathrm{n}(\%)$} \\
\hline cT1 & $1138(75.3)$ & $737(78.0)$ & $401(70.7)$ & \multirow[t]{2}{*}{$<0.0001$} \\
\hline cT2a & $374(24.7)$ & $208(22.0)$ & $166(29.3)$ & \\
\hline
\end{tabular}

had pT3 tumours, $10(0.7 \%)$ had lymph node metastases, and $707(46.8 \%)$ had one or more of Gleason score $\geq 7$, pT3, or nodal metastases (Table 2). Based on univariable analysis, patients who satisfied all PRIAS criteria were less likely to have Gleason score $\geq 7$ (odds ratio [OR] 0.61; 95\% confidence interval $[\mathrm{Cl}]$ 0.49-0.75), pT3 (OR 0.41; $95 \% \mathrm{Cl}$ $0.31-0.55)$, nodal metastases (OR 0.37; 95\% Cl 0.10-1.31), or any adverse finding (OR 0.56; 95\% Cl 0.4-0.69). Associations between baseline factors (age, preoperative PSA, PSAD, number of positive biopsy cores, and clinical stage) and pathological outcomes are presented in Table 3. All baseline variables were associated with increased risk of Gleason score $\geq 7$ and pT3, and the majority of these associations were statistically significant. On multivariable analysis, the associations between age, PSA, and number of cores positive with Gleason score $\geq 7$ and $\mathrm{pT} 3$ remained statistically significant.

\section{Recurrence}

Patients who met the PRIAS criteria (PRIAS-eligible), were less likely to have a positive surgical margin ( $n=83,8.9 \%)$ compared to PRIAS-ineligible patients $(n=77,13.6 \%$; relative risk [RR] $0.64 ; 95 \% \mathrm{Cl} 0.48-0.87)$. At a median follow up of 3.7 years post-surgery, $72(4.8 \%)$ patients were diagnosed with PSA recurrence, 24 (1.6\%) patients received

\begin{tabular}{|c|c|c|c|c|c|}
\hline Outcome & $\begin{array}{l}\text { Total } \\
\text { n (\%) }\end{array}$ & $\begin{array}{c}\text { PRIAS-eligible } \\
\text { n (\%) }\end{array}$ & $\begin{array}{c}\text { PRIAS-ineligible } \\
\text { n (\%) }\end{array}$ & $\begin{array}{c}\text { OR }^{\mathrm{a}} \\
(95 \% \mathrm{Cl})\end{array}$ & $\mathbf{p}$ \\
\hline \multicolumn{6}{|c|}{ Gleason sum } \\
\hline 6 & $837(55.4)$ & $563(59.6)$ & $274(48.3)$ & \multirow{3}{*}{$0.61(0.49-0.75)$} & \multirow{3}{*}{$<0.0001$} \\
\hline$\geq 7$ & $651(43.7)$ & $362(38.3)$ & $289(51.0)$ & & \\
\hline Missing & $24(1.6)$ & $20(2.1)$ & $4(0.7)$ & & \\
\hline \multicolumn{6}{|c|}{ Pathological stage } \\
\hline pT2 & $1289(85.3)$ & $845(89.4)$ & $444(78.3)$ & \multirow{3}{*}{$0.41(0.31-0.55)$} & \multirow{3}{*}{$<0.0001$} \\
\hline рT3 & $219(14.5)$ & $96(10.2)$ & $123(21.7)$ & & \\
\hline Missing & $4(0.3)$ & $4(0.4)$ & $0(0)$ & & \\
\hline \multicolumn{6}{|c|}{ Lymph node metastases } \\
\hline NO & 1087 (71.9) & $700(74.1)$ & 387 (68.3) & \multirow{3}{*}{$0.39(0.10-1.31)$} & \multirow{3}{*}{0.1238} \\
\hline N1 & $10(0.7)$ & $4(0.4)$ & $6(1.1)$ & & \\
\hline $\mathrm{Nx}$ & $415(27.4)$ & $241(25.5)$ & $174(30.7)$ & & \\
\hline \multicolumn{6}{|c|}{ Composite outcome ${ }^{b}$} \\
\hline No & $804(53.2)$ & $554(58.6)$ & $250(44.1)$ & \multirow{3}{*}{$0.56(0.45-0.69)$} & \multirow{3}{*}{$<0.0001$} \\
\hline Yes & 707 (46.8) & $390(41.3)$ & $317(55.9)$ & & \\
\hline Missing & $1(0.07)$ & $1(0.1)$ & $0(0)$ & & \\
\hline
\end{tabular}


Active surveillance for prostate cancer

\begin{tabular}{|c|c|c|c|c|}
\hline \multicolumn{5}{|l|}{ Univariable associations } \\
\hline \multirow[b]{2}{*}{ Variable } & \multicolumn{4}{|c|}{$\begin{array}{l}\text { Outcome } \\
\text { OR (95\% Cl) }\end{array}$} \\
\hline & Gleason sum $\geq 7$ & Pathological stage pT3 & Lymph node metastases & Composite outcome $^{a}$ \\
\hline Age (1 unit increase) & $1.04(1.02-1.05)$ & $1.04(1.02-1.06)$ & $1.05(0.95-1.15)$ & $1.04(1.02-1.05)$ \\
\hline Preoperative PSA (1 unit increase) & $1.13(1.07-1.18)$ & $1.13(1.05-1.20)$ & $1.13(0.84-1.52)$ & $1.04(1.08-1.19)$ \\
\hline \multicolumn{5}{|l|}{ Clinical stage } \\
\hline $\mathrm{T} 2$ & $1.00(0.79-1.27)$ & $1.14(0.83-1.58)$ & $2.81(0.81-9.79)$ & $1.04(0.83-1.32)$ \\
\hline T1 & 1.00 & 1.00 & 1.00 & 1.00 \\
\hline \multicolumn{5}{|l|}{ PSA density } \\
\hline$\geq 0.20$ & $1.74(1.19-2.54)$ & $2.03(1.30-3.18)$ & $1.54(0.19-12.35)$ & $1.76(1.20-2.57)$ \\
\hline$<0.20$ & 1.00 & 1.00 & 1.00 & 1.00 \\
\hline \multicolumn{5}{|l|}{ Number of positive cores } \\
\hline$>2$ & $1.48(1.19-1.84)$ & $2.24(1.68-3.00)$ & $2.25(0.64-7.84)$ & $1.66(1.34-2.06)$ \\
\hline$\leq 2$ & 1.00 & 1.00 & 1.00 & 1.00 \\
\hline \multicolumn{5}{|l|}{ Multivariable associations } \\
\hline & \multicolumn{4}{|c|}{$\begin{array}{l}\text { Outcome } \\
\text { OR (95\% Cl) }\end{array}$} \\
\hline & Gleason sum $\geq 7$ & Pathological stage pT3 & Lymph node metastases & Composite outcome ${ }^{a}$ \\
\hline Age (1 unit increase) & $1.03(1.02-1.05)$ & $1.03(1.01-1.05)$ & $N / A^{b}$ & $1.03(1.02-1.05)$ \\
\hline Preoperative PSA (1 unit increase) & $1.10(1.04-1.16)$ & $1.09(1.02-1.18)$ & $N / A^{b}$ & $1.11(1.06-1.17)$ \\
\hline \multicolumn{5}{|l|}{ Clinical stage } \\
\hline $\mathrm{T} 2$ & $1.02(0.80-1.30)$ & $1.09(0.78-1.53)$ & $N / A^{b}$ & $1.06(0.83-1.35)$ \\
\hline T1 & 1.00 & 1.00 & $N / A^{b}$ & 1.00 \\
\hline \multicolumn{5}{|l|}{ PSA density } \\
\hline$\geq 0.20$ & $1.39(0.92-2.11)$ & $1.69(1.03-2.79)$ & $N / A^{b}$ & $1.38(0.91-2.09)$ \\
\hline$<0.20$ & 1.00 & 1.00 & $N / A^{b}$ & 1.00 \\
\hline \multicolumn{5}{|l|}{ Number of positive cores } \\
\hline$>2$ & $1.47(1.17-1.84)$ & $2.23(1.66-2.99)$ & $N / A^{b}$ & $1.65(1.32-2.07)$ \\
\hline$\leq 2$ & 1.00 & 1.00 & $N / A^{b}$ & 1.00 \\
\hline
\end{tabular}

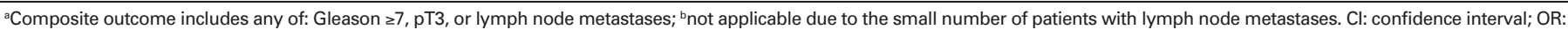
odds ratio; PSA: prostate-specific antigen.

pelvic radiation, and $13(0.9 \%)$ patients received androgen deprivation. Recurrence-free survival estimates were similar between PRIAS-eligible and PRIAS-ineligible cohorts (hazard ratio [HR] 0.71; 95\% Cl 0.46-1.09; Fig. 2).

\section{Death}

There were no prostate cancer-related deaths in either the PRIAS-eligible or PRIAS-ineligible cohorts, but 31 (2.1\%) patients died from other causes (Fig. 3). There was no significant difference in overall survival between PRIAS-eligible and PRIAS-ineligible cohorts (HR 0.72; 95\% Cl 0.36-1.47; Fig. 3).

\section{Discussion}

Active surveillance of prostate cancer aims to prevent invasive therapy in patients with clinically insignificant tumours. ${ }^{14}$ Indeed, a significant proportion of patients are diagnosed with clinically low-risk prostate cancer and all of these men may consider surveillance a viable management approach; ${ }^{5}$ however, we also know that a consider- able proportion of men with clinically low-risk disease will have higher-stage or grade tumours than predicted..$^{15}$ The low recurrence rate and long survival experienced by this cohort is consistent with other studies of clinically lowrisk patients treated with radical prostatectomy. ${ }^{16,17}$ Delay in treatment may impact long-term cure for some of these men. ${ }^{18}$ In this study, among patients clinically classified as low-risk, approximately $47 \%$ were found to have higher-risk disease when the prostatectomy specimen was examined.

The PRIAS criteria aim to stratify patients with prostate cancer to identify those at lowest risk of disease misclassification or progression. Patients in our cohort who satisfied all PRIAS criteria were less likely to harbour intermediateor high-risk tumours compared to those who did not meet PRIAS criteria ( $41 \%$ vs. $56 \%$, respectively), indicating that PRIAS-eligible patients are at less risk of disease misclassification compared to PRIAS-ineligible patients. This finding is consistent with recent reports assessing the utility of PRIAS criteria in smaller cohorts, cohorts that include patients in the active surveillance era, and cohorts that include intermediate clinical risk. ${ }^{19-29}$ While these data suggest that 


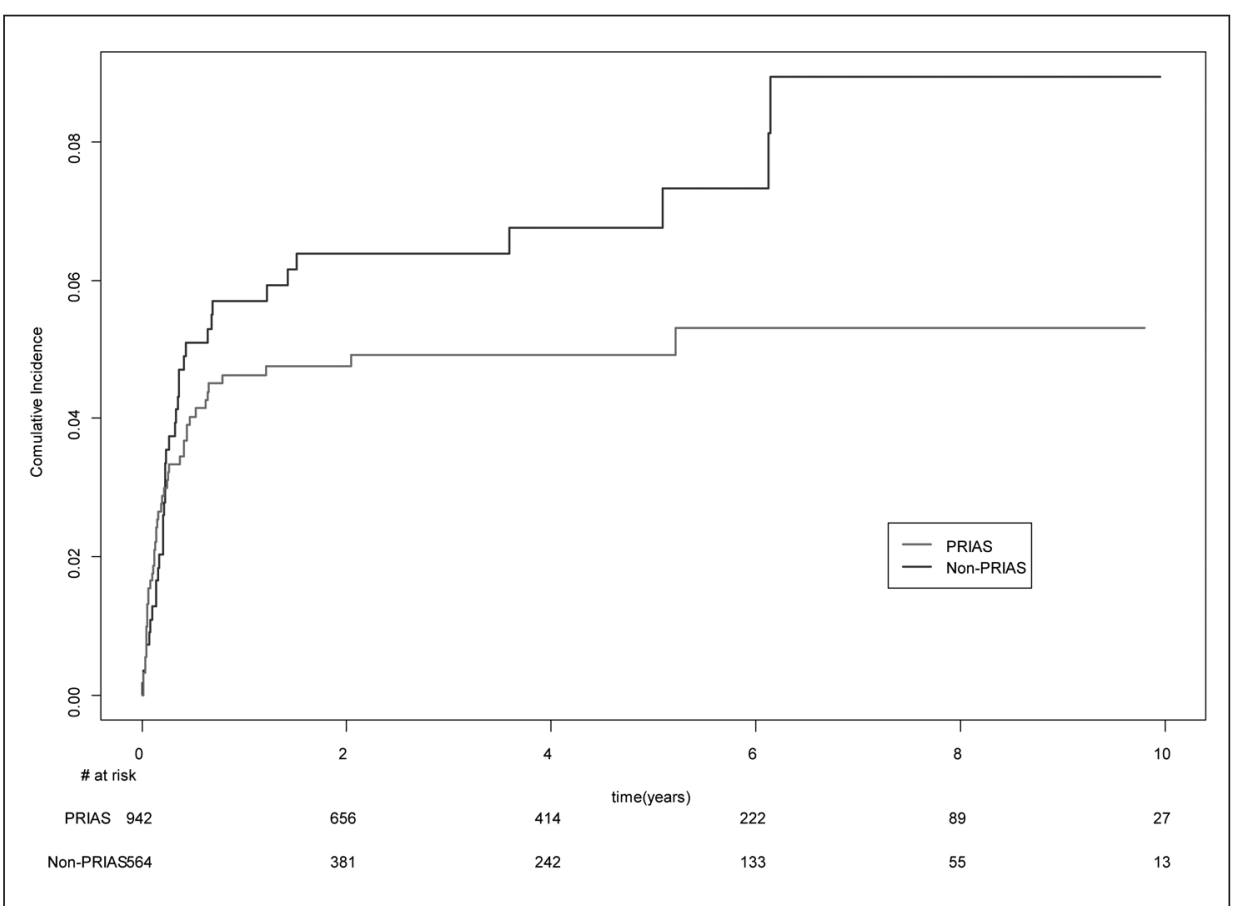

Fig. 2. Cumulative incidence of time to recurrence among PRIAS-eligible vs. PRIAS-ineligible cohorts. PRIAS: Prostate Cancer Research International: Active Surveillance.

PRIAS criteria are useful, there is clear room for improvement to help best select patients for active surveillance.

It is important to recognize that this study may overestimate the risk of under-grading or under-staging contemporary low-risk patients. Many patients undergo a confirma-

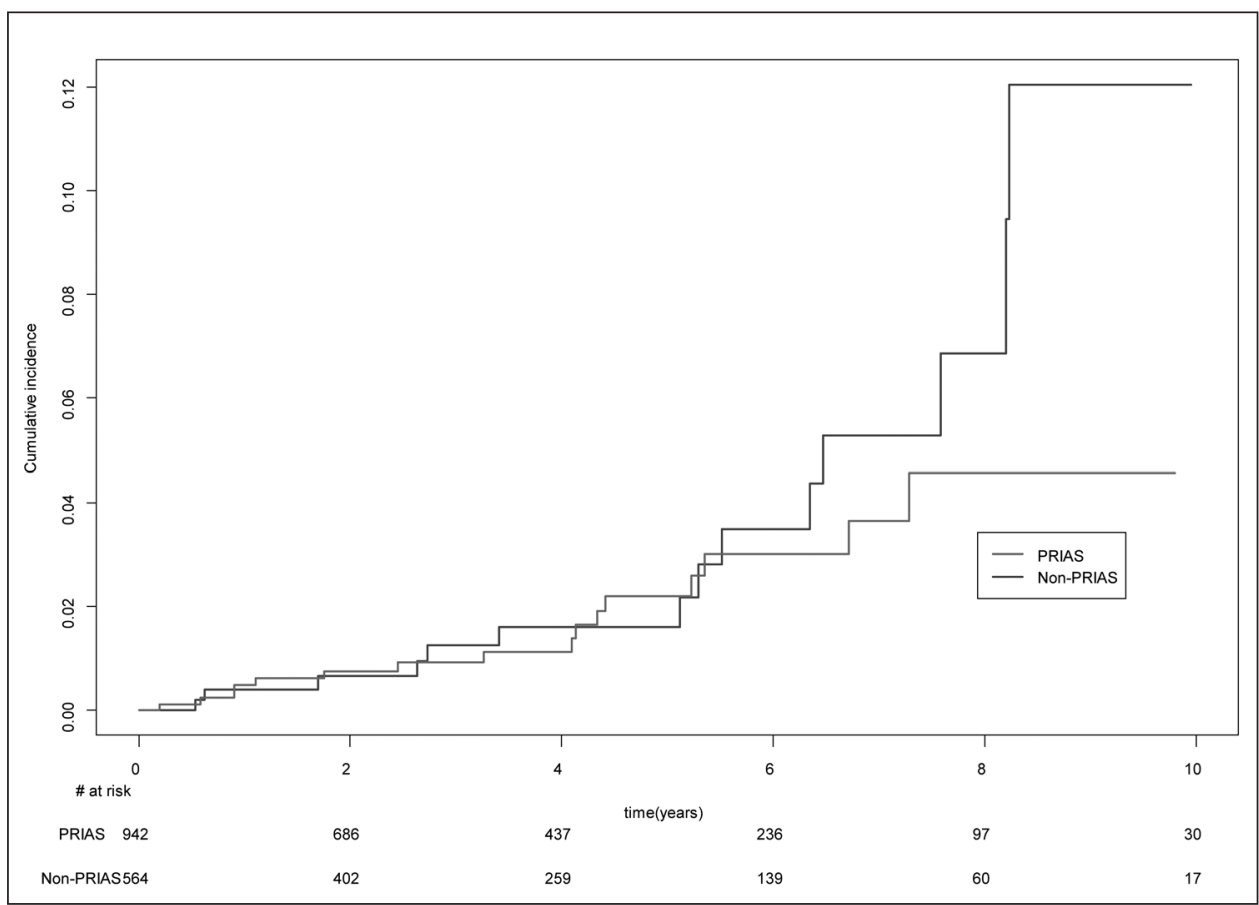

Fig. 3. Cumulative incidence of time to death among PRIAS-eligible vs. PRIAS-ineligible cohorts. PRIAS: Prostate Cancer Research International: Active Surveillance. tory biopsy within 12 months of their initial biopsy prior to being considered eligible for active surveillance. This confirmatory biopsy reclassifies approximately $20-25 \%$ of patients. In addition, prostate magnetic resonance imaging and other diagnostic tests may be used to decrease the risk of misclassification. ${ }^{30-33}$ Furthermore, the estimates in this study were derived from a prostatectomy cohort. It is possible that there are other factors, such as rate of PSA change or proportion of cancer, that may influence a patient's treatment selection. Applying these data to patients who chose non-surgical treatments may not be valid.

Among clinically low-risk patients, older age, higher PSA, and an increased number of positive biopsy cores was independently associated with risk of adverse prostatectomy pathology. Interestingly, the associations for PSAD and clinical stage were not significant when adjusted for other clinical factors. In PRIAS, a PSAD threshold of 0.2 is used; however, a recent review of the predictive performance of PSAD revealed that decreasing the PSA threshold to $0.15 \mathrm{mg} / \mathrm{mL}$ or lower would increase the detection of advanced disease. ${ }^{19}$ Further study to optimize clinical factors and thresholds is therefore warranted. ${ }^{34}$

Finally, the findings of this study may be limited because some patients did not have prostate volume documented and were therefore excluded from analysis. We do not know if the patients in this study are different from patients without a documented prostate volume. Also, since the median followup time for this study was 3.7 years, we cannot be certain of the proportion of patients with higher Gleason grade, extraprostatic extension, or lymph node metastases that would develop clinical symptoms or die from prostate cancer within their lifetime.

\section{Conclusion}

Active surveillance may be underused because of concerns of disease misclassification. In this study, clinically low-risk patients that met 
all PRIAS criteria were less likely to have pathologically intermediate- or high-risk cancer at prostatectomy compared to those who did not meet all PRIAS criteria. Higher PSA and greater than two positive biopsy cores were independently predictive of disease misclassification among lowrisk patients. Future studies to further optimize selection of patients for active surveillance are warranted.

Competing interests: Dr. Cagiannos has been an advisor for and received honoraria from AbbVie and Ferring. Dr. Lavallée has been an advisor for Ferring and Sanofi and received a grant from Sanofi. Dr. Morash has been an advisor for AbbVie, Astellas, Ferring, Janssen, and Sanofi. The remaining authors report no competing personal or financial interests.

This paper has been peer-reviewed.

\section{References}

1. Bray F, Lortet-Tieulent J, Ferlay J, et al. Prostate cancer incidence and mortality trends in 37 European countries: An overview. Eur J Cancer 2010;46:3040-52. https://doi.org/10.1016/i.eica.2010.09.013

2. Lin K, Croswell JM, Koenig H, et al. Prostate-specific antigen-based screening for prostate cancer: An evidence update for the U.S. preventive services task force: Agency for Healthcare Research and Quality Rockville; 2011.

3. Thompson I, Thrasher JB, Aus $G$, et al. Guideline for the management of clinically localized prostate cancer: 2007 update. J Urol 2007;177:2106-31. https://doi.org/10.1016/i.juro.2007.03.003

4. Heidenreich A, Bellmunt J, Bolla M, et al. EAU guidelines on prostate cancer. Part 1: Screening, diagnosis, and treatment of clinically localized disease. Eur Urol 2011;59:61-71. https://doi.org/10.1016/i eururo.2010.10.039

5. Morash C, Tey R, Agbassi C, et al. A quality initiative of the program in evidence based care (PEBC), Cancer Care Ontario (CCO) - Active surveillance for the management of localized prostate cancer. Cancer Care Ontario 2014. Available at https://www.cancercare.on.ca/common/pages/UserFile. aspx?fileld=325696. Accessed July 4, 2017.

6. Dall'Era MA, Konety BR, Cowan JE, et al. Active surveillance for the management of prostate cancer in a contemporary cohort. Cancer 2008; 112:2664-70. hitps://doi.org/10.1002/cncr.23502

7. Klotz L, Zhang L, Lam A, et al. Clinical results of long-term followup of a large, active surveillance cohort with localized prostate cancer. J Clin Oncol 2010;28:126-31. https://doi.org/10.1200/JC0.2009.24.2180

8. Soloway MS, Soloway CT, Eldefrawy A, et al. Careful selection and close monitoring of low-risk prostate cancer patients on active surveillance minimizes the need for treatment. Eur Urol 2010;58:831-5. https://doi.org/10.1016/i.eururo.2010.08.027

9. Tosoian JJ, Trock BJ, Landis P, et al. Active surveillance program for prostate cancer: An update of the Johns Hopkins experience. J Clin Oncol 201 1;29:2185-90. https://doi.org/10.1200/JC0.2010.32.8112

10. Godtman RA, Holmberg E, Khatami A, et al. Outcome following active surveillance of men with screendetected prostate cancer. Results from the Göteborg randomized, population-based prostate cancer screening trial. Eur Urol 2013;63:101-7. https://doi.org/10.1016/j.eururo.2012.08.066

11. Selvadurai $E D$, Singhera $M$, Thomas $K$, et al. Medium-term outcomes of active surveillance for localized prostate cancer. Eur Urol 2013;64:981-7. hitps://doi.org/10.1016/i.eururo.2013.02.020

12. Bangma $\mathrm{CH}, \mathrm{Bul} M$, Roobol M. The Prostate Cancer Research International: Active Surveillance study. Curr Opin Urol 2012;22:216-21. https://doi.org/10.1097/MOU.0b013e328351dec7

13. van den Bergh RC, Roemeling S, Roobol MJ, et al. Prospective validation of active surveillance in prostate cancer: The PRIAS study. Eur Urol 2007;52:1560-3. https://doi.org/10.1016/i.eururo.2007.05.011

14. Choo R, Klotz L, Danjoux C, et al. Feasibility study: Watchful waiting for localized, low-to-intermediate-grade prostate carcinoma with selective delayed intervention based on prostate-specific antigen, histological, and/ or clinical progression. J Urol 2002;167:1664-9. https://doi.org/10.1016/S0022-5347(05)65174-9

15. Suardi N, Capitanio U, Chun FK, et al. Currently used criteria for active surveillance in men with low-risk prostate cancer. Cancer 2008;113:2068-72. https://doi.org/10.1002/cncr.23827

16. Stephenson AJ, Kattan MW, Eastham JA, et al. Prostate cancer-specific mortality after radical prostatectomy for patients treated in the prostate-specific antigen era. J Clin Oncol 2009;27:4300-5. https://doi.org/10.1200/JC0.2008.18.2501

17. Boorijan $S A$, Eastham $J A$, Graefen $M$, et al. A critical analysis of the long-term impact of radical prostatectomy on cancer control and function outcomes. Eur Urol 2012;61:664-75. https://doi.org/10.1016/i. eururo.2011.11.053
18. Weiner AB, Patel SG, Eggener SE. Pathological outcomes for low-risk prostate cancer after delayed radical prostatectomy in the U.S. Paper presented at: Urologic Oncology: Seminars and Original Investigations 2015. https://doi.org/10.1016/j.urolonc.2014.12.012

19. Ha Y-S, Yu J, Salmasi AH, et al. Prostate-specific antigen density toward a better cutoff to identify better candidates for active surveillance. Urology 2014;84:365-72. https://doi.org/10.1016/i.urology.2014.02.038

20. Wong L, Neal D, Johnston R, et al. International multicentre study examining selection criteria for active surveillance in men undergoing radical prostatectomy. Brit J Cancer 2012;107:1467-73. https://doi.org/10.1038/bic.2012.400

21. Kim TH, Jeon HG, Choo SH, et al. Pathological upgrading and upstaging of patients eligible for active surveillance according to currently used protocols. Int J Urol 2014;21:377-81. https://doi.org/10.1111/ ïu. 12326

22. Mitsuzuka K, Narita S, Koie T, et al. Pathological and biochemical outcomes after radical prostatectomy in men with low-risk prostate cancer meeting the Prostate Cancer International: Active surveillance criteria. BJU Int 2013;111:914-20. https://doi.org/10.1111/i.1464-410X.2012.11658.x

23. Kates M, Tosoian JJ, Trock BJ, et al. Indications for intervention during active surveillance of prostate cancer: A comparison of the Johns Hopkins and Prostate Cancer Research International Active Surveillance (PRIAS) protocols. BJU Int 2015;115:216-22. https://doi.org/10.1111/bju.12828

24. Russo Gl, Cimino S, Castelli T, et al. Percentage of cancer involvement in positive cores can predict unfavorable disease in men with low-risk prostate cancer but eligible for the Prostate Cancer International: Active surveillance criteria. Urol Oncol 2014;32:291-6. https://doi.org/10.1016/i.urolonc.2013.07.004

25. Busch J, Magheli A, Leva N, et al. Higher rates of upgrading and upstaging in older patients undergoing radical prostatectomy and qualifying for active surveillance. BJU Int 2014;114:517-21. https://doi.org/10.1111/bju.12466

26. Müller $G$, Bonkat $G$, Rieken $M$, et al. Potential consequences of low biopsy core number in selection of patients with prostate cancer for current active surveillance protocols. Urology 2013;81:837-43. https://doi.org/10.1016/i.urology.2012.10.068

27. Vellekoop A, Loeb S, Folkvaljon Y, et al. Population-based study of predictors of adverse pathology among candidates for active surveillance with Gleason 6 prostate cancer. J Urol 2014;191:350-7. https://doi.org/10.1016/i.juro.2013.09.034

28. Iremashvili V, Pelaez L, Manoharan M, et al. Pathological prostate cancer characteristics in patients eligible for active surveillance: A head-to-head comparison of contemporary protocols. Eur Urol 2012;62:462-8. https://doi.org/10.1016/i.eururo.2012.03.011

29. El Haij A, Ploussard G, Taille A, et al. Analysis of outcomes after radical prostatectomy in patients eligible for active surveillance (PRIAS). BJU Int 2013;111:53-9. https://doi.org/10.1111/i.1464410X.2012.11276.x

30. Berglund RK, Masterson TA, Vora KC, et al. Pathological upgrading and up staging with immediate repeat biopsy in patients eligible for active surveillance. J Urol 2008; 180:1964-7. https://doi.org/10.1016/i. juro.2008.07.051

31. Porten SP, Whitson JM, Cowan JE, et al. Changes in prostate cancer grade on serial biopsy in men undergoing active surveillance. J Clin Oncol 2011;29:2795-800. https://doi.org/10.1200/JC0.2010.33.0134

32. Bul M, van den Bergh RC, Rannikko A, et al. Predictors of unfavourable repeat biopsy results in men participating in a prospective active surveillance program. Eur Urol 2012;61:370-7. https://doi.org/10.1016/i.eururo.2011.06.027

33. Venkitaraman R, Norman A, Woode-Amissah R, et al. Predictors of histological disease progression in untreated, localized prostate cancer. J Urol 2007;178:833-7. https://doi.org/10.1016/i. juro.2007.05.038

34. Loeb S. Prostate-specific antigen density toward a better cutoff to identify better candidates for active surveillance. Urology 2014;84:371-2. https://doi.org/10.1016/j.urology.2014.02.039

Correspondence: Dr. Rodney H. Breau, Division of Urology, Department of Surgery, Ottawa, ON, Canada; rbreau@toh.on.ca

To answer the three multiple-choice questions associated with this review article, go to: https://www.qzzr.com/c/quiz/434743/claim-section-3-self-assessment-credits-for-readingcuaj-08-17

This program is an Accredited Self-Assessment Program (Section 3) as defined by the Maintenance of Cerrification Program of The Royal College of Physicians \& Surgeons of Canada, and approved by the Canadian Urological Association. Remember to visit MAINPORT (www.mainport.org/ mainport/) to record your learning and outcomes. You may claim a maximum of 1 hour of credit. 